\title{
AKTIVITAS ASAP CAIR CANGKANG BUAH Hevea braziliensis SEBAGAI ANTI BAKTERI Staphylacoccus aureus
}

\author{
Widiya Agustina*1, Sumpono ${ }^{2}$, Rina Elvia ${ }^{3}$ \\ 1,2,3 Program Studi Pendidikan Kimia Jurusan Matematika dan Ilmu Pengetahuan \\ Fakultas Keguruan dan Ilmu Pendidikan Universitas Bengkulu \\ *11e-mail: widiyaagustina1@gmail.com,
}

\begin{abstract}
The aims of this research is to know the activity of liquid smoke Hevea braziliensis Seed Shell as antibacterial of Staphylacoccus aureus. The synthesis of liquid smoke on this research through some process such as pyrolysis, sedimentation, filtration, distillation and redistillation. H.braziliensis Seed Shell liquid smoke obtained phenol levels $0.84 \%$ and $\mathrm{pH} 2.548$. Antibacterial activity tested by hollow difusion methode with variations concentration of liquid smoke at $5 \%,, 10,25,50,75$, and $100 \% \mathrm{v} / \mathrm{v}$. The effective concentration H.braziliensis liquid smoke in inhibiting the growth of S. aureus bacteria is $75 \% \mathrm{v} / \mathrm{v}$ with strong antibacterial level that showed by an inhibition zone at $10,6 \mathrm{~mm}$. On this research One Way ANOVA test showing the $\mathrm{F}_{\text {count }} \geq \mathrm{F}$ table, which means there is a significant difference between the diameter of the inhibition zone on various concentrations of H.braziliensis seed shell.iquid smoke..
\end{abstract}

Keywords : Liquid smoke, Hevea braziliensis, antibacterial, Staphylacoccus aureus

\begin{abstract}
Abstrak
Penelitian ini bertujuan untuk mengetahui aktivitas asap cair cangkang buah Hevea braziliensis sebagai antibakteri Staphylacoccus aureus. Pada penelitian ini pembuatan asap cair dilakukan bebrapa proses yaitu pirolisis, sedimentasi, penyaringan, destilasi dan redestilasi. Asap cair cangkang buah $H$ braziliensis pada penelitian ini memiliki kadar fenol sebesar $0,84 \%$ dan $\mathrm{pH} 2,548$. Uji aktivitas antibakteri dilakukan dengan metode difusi sumuran dengan berbagai variasi konsentrasi asap cair cangkang buah karet yaitu 5, 10, 25, 50, 75, dan 100\%,. Konsentrasi efektif asap cair cangkang buah $H$ braziliensis dalam menghambatpertumbuhan bakteri S. aureus adalah $75 \%$ dengan kekuatan daya antibakteri kuat yang ditandai dengan zona bening yang terbentuk sebesar 10,6 mm. Hasil uji One Way ANOVA menunjukan bahwa $\mathrm{F}_{\text {hitung }} \geq \mathrm{F}_{\text {tabel }}$, artinya terdapat pengaruh yang signifikan antara diameter zona bening terhadap variasi konsentrasi asap cair cangkang buah $H$ braziliensis .
\end{abstract}

Kata kunci : Asap ciar, Hevea braziliensis, antibakteri, Staphylacoccus aureus

\section{PENDAHULUAN}

Metabolit sekunder dari bahan alam merupakan sumber yang sangat kaya khususnya sebagai sumber alternatif anti bakteri [1]. Salah satu tanaman yang telah luas dimanfaatkan adalah karet (Hevea braziliensis ), dengan produk utama berupa lateks. Selain lateks tanaman H.braziliensis selama hidupnya juga menghasilkan daun dan buah yang cukup banyak. Hingga saat ini cangkang buah $H$.braziliensis belum dimanfaatkan secara optimal bahkan kadangkala menjadi suatu limbah yang tidak memiliki nilai jual. [2]. Cangkang buah H.braziliensis memiliki struktur yang sangat keras juga memiliki kandungan senyawa aromatik dan mengandung senyawa asam yang lebih banyak dibandingkan dengan kayu lunak. Komponen cangakang buah H.braziliensis antara lain adalah hemiselulosa $(18,00 \%)$, selulosa $(61,04 \%)$ dan lignin $(21,60 \%)$ [3]. Kandungan lignin yang tinggi akan sangat berguna bila ingin memanfaatkan cangkang buah H.braziliensis sebagai bahan baku karbon aktif .
Pembuatan cangkang buah H.braziliensis menjadi arang aktif akan menghasilkan limbah berupa asap yang dalam bentuk cairan yang sering disebut asap cair. Komponen senyawa yang ter-dapat pada asap cair terdiri dari beberapa kelompok yaitu fenol dan turunannya, karbonil (keton dan aldehid), asam dan derivat asam asam organik, hidrokarbon polisiklis aromatis ( PAH) $[4,5]$. Selain itu asap cair juga mengandung senyawa yang berbahaya yaitu tar yang berwarna hitam pekat dan benzopirin sehingga harus dilakukan pemisahan dari asap cair dalam penggunaannya. Adanya kandungan fenol dan asam organik dalam suatu bahan akan memberikan potensi keaktifan bahan tersebut sebagai sebagai antibakteri. [6]

Bakteri Staphylacoccus aureus merupakan salah satu bakteri yang biasa hidup dipermukaan tubuh yang dapat menyebabkan infeksi kulit apabila terjadi luka pada kulit [7].

Dari paparan di atas maka dianggap perlu dilakukan penelitian mengenai aktifitas antibakteri asap cair cangkang buah $H$. braziliensis terhadap $S$. aureus 


\section{METODE PENELITIAN}

Bahan-bahan yang digunakan pada peneli- tian ini cangkang buah H.braziliensis, koleksi biakan murni bakteri S.aureus dari Laboratorium Basic Science Universitas Bengkulu, NA (Merck), NB (Merck), indikator phenolftalien, serbuk $\mathrm{NaOH} \mathrm{0,1} \mathrm{N} \mathrm{(Merck),}$ aquades, kertas saring whatmann No.41, padatan kristal fenol (Merck), serbuk $\mathrm{FeCl}_{3} 1 \%$ (Merck), serbuk $\mathrm{Na}_{2} \mathrm{CO}_{3} 5 \%$ (Merck), cairan alkohol 96\%, reagen FolinCiocalteu (Merck), serbuk asam oksalat 0,1 N (Merck).

Alat-alat yang digunakan pada penelitian ini yaitu cawan petri, alat produksi asap cair milik Program Studi S2 Pendidikan IPA Universitas Bengkulu, labu destilasi, kondensor, jarum ose, pipet mikro, pembakar spritus, hot plate, neraca analitik (Kem ABJ 220-4NN), inkubator, laminar air flow, shaker, vortex, piknometer, autoklaf, kompor gas, labu ukur, botol semprot, colony counter, spektrofotometer Uv-Vis (Thermo Scientific Evolution 201), dan magnetic stirer.

Untuk mendapatkan cair, cangkang buah H.braziliensis yang digunakan pada penelitian ini dikecilkan ukurannya dan dipirolisis selama 12 jam. Setelah dilakukan pirolisis kemudian dilaku kan proses sedimentasi, filtrasi dan destilasi. Proses sedimentasi dilakukan dengan menempatkan asap cair pada botol kaca selama 7 hari. Proses sedimentasi bertujuan untuk mengendapkan tar yang bersifat toksik dan karsinogenik. Setelah 7 hari selanjutnya dilakukan proses filtrasi menggunakan kertas saring whatmann no. 41, filtrate yang dihasilkan didestilasi dan redestilasi pada suhu $200{ }^{\circ} \mathrm{C}$ dengan tujuan meminimalkan kandungan tar dan senyawa PAH (polisiklik aromatis hidrokarbon) yang dihasilkan saat pirolisis. Asap cair hasil redestilasi kemudian diukur $\mathrm{pH}$ nya meng-gunakan $\mathrm{pH}$ meter. Selanjutnya menimbang $0,5 \mathrm{~g}$ asap cair, dilarutkan ke dalam $5 \mathrm{~mL}$ aquades. Setelah itu dipanaskan hingga mendidih dan ditambahkan beberapa tetes $\mathrm{FeCl}_{3}$ $1 \%$. Uji positif terbentuknya warna hijau, merah, ungu, biru atau hitam pekat menunjukkan adanya fenol [8].

Untuk penentuan kadar fenol pertama- tama dilakukan pembuatan kurva standar fenol. Menimbang fenol murni $0,01 \mathrm{~g}$ lalu dilarutkan menggunakan aquades hingga volumenya $100 \mathrm{~mL}$ sehingga didapatkan larutan fenol dengan konsentrasi $100 \mathrm{ppm}$ Kemudian dipipet sebanyak $0,1,0,2,0,3,0,4$, dan 0,5 $\mathrm{mL}$ larutan, dan diletakkan pada tabung reaksi. Larutan yang belum mencapai volume $0,5 \mathrm{~mL}$, ditambahkan dengan aquades masing-masing secara berurutan 0,4 , $0,3,0,2,0,1$ dan $0 \mathrm{~mL}$. Kemudian pada semua tabung ditambahkan $0,5 \mathrm{~mL}$ reagen Folin-Ciocalteu dan didiamkan selama 3 menit. Setelah itu ditam-bahkan kembali $1 \mathrm{~mL}$ larutan $\mathrm{Na}_{2} \mathrm{CO}_{3} 5 \%$ dan di vortex. Kemudian diukur absorbansinya dengan panjang gelombang 766 dan dibuat kurva kalibrasinya yang merupakan hubungan antara kon-sentrasi fenol $(\mathrm{mg} / \mathrm{L})$ dengan absorban [9]. Selanjutnya dipipet asap cair sebanyak $50 \mu \mathrm{L}$ diencerkan menggunakan aquades hingga volume $20 \mathrm{~mL}$. kemudian dipipet sebanyak 0,5 $\mathrm{mL}$ dan diletakan pada tabung reaksi, ditambahkan 0,5 $\mathrm{mL}$ reagen Folin-Ciocalteu, dikocok dan didiamkan selama 3 menit. Menambahkan kembali $1 \mathrm{~mL} \mathrm{Na}_{2} \mathrm{CO}_{3}$ $5 \%$. Lalu sampel dikocok kembali dan diukur absorbansinya dan ditentukan kadar fenol yang ada.

Untuk uji anti bakteri, maka semua alat-alat yang terbuat dari kaca seperti cawan petri, erlenmayer, pipet ukur disterilisasi menggunakan autoklaf pada suhu $121^{\circ} \mathrm{C}$ selama 15 menit. Kawat ose disterilkan dengan pembakaran langsung di atas lampu spritus. Untuk bahan yang terbuat dari karet disterilkan dengan cara direndam dalam alkohol $96 \%$. Untuk pembuatan media tumbuh bak-teri, ditimbang masing masing sebanyak $7 \mathrm{~g}$ serbuk NA dan 5 gram serbuk NB kemudian masing-masing ditambahkan aquades sebanyak $250 \mathrm{~mL}$ dipanaskan hingga semua bahan larut dan homogen. Media NA dan NB yang telah dibuat disterilkan dengan menggunakan autoklaf pada suhu $121^{\circ} \mathrm{C}$ selama 15 menit.

Mengambil 1 ose isolat bakteri kemudian memasukkannya ke dalam media NB $250 \mathrm{~mL}$ yang telah disterilkan. Lalu media NB tersebut ditutup dengan kapas dan di wrap plastik dan di shaker selama 24 jam pada suhu $37{ }^{\circ} \mathrm{C}$. Penentuan efektivitas antibakteri terhadap $S$. aureus dilakukan dengan metode difusi agar menggunakan cara sumuran dengan konsentrasi larutan uji asap cair yaitu 100, 75, 50, 25, 10, dan 5\%.v/v. Data yang diperoleh selanjutnya diolah secara statistik data diameter zona bening asap cair cangkang buah H.braziliensi terhadap pertumbuhan S.aureus menggunakan Uji One Way Anova.

\section{HASIL DAN PEMBAHASAN}

Penelitian ini dilaksanakan di laboratorium FKIP Kimia UNIB, SBIH Ruyani, dan Laboratorium FKIK UNIB dari bulan Februari sampai Mei 2017. Sampel yang digunakan pada penelitian ini yaitu cangkang buah H.braziliensis diambil dari perkebunan warga di Sukaraja Provinsi Bengkulu yang sudah tua.

Pada penelitian ini didapatkan asap cair hasil pirolisis cangkang buah H.braziliensis sebanyak 815 $\mathrm{ml}$ atau rendamen $42,01 \%$, rendamen arang sebanyak $21,65 \%$ dan rendaman asap yang tidak terkondensasikan yaitu sebanyak 36,34\%. Asap yang tidak terkondensasikan merupakan senyawa yang mudah menguap dan merupakan senyawa yang tidak dapat dikondensasikan dengan air sebagai medium pendingin.

Pada penelitian ini asap cair yang diperoleh berwarna coklat kehitaman dan terdapat tar yang berwarna hitam pekat. Sifat fisik asap cair cangkang buah 
H.braziliensis hasil pirolisis dan dapat dilihat pada Tabel 1.

Tabel.1. Rendamen dan data sifat fisik asap cair cangkang buah H.braziliensis

\begin{tabular}{lc}
\hline \multicolumn{1}{c}{ Parameter } & Data \\
\hline Rendamen asap cair & $42,01 \%$ \\
Warna & Coklat kehitaman \\
Bau & Asap menyengat \\
\hline
\end{tabular}

Selanjutnya dilakukan proses sedimentasi/ pengendapan selama 7 hari untuk mengurangi kadar tar didalam asap cair. Proses sedimentasi menghasilkan rendamen sebesar 41\%. Setelah dilakukan proses sedimentasi, selanjutnya asap cair disaring menggunakan kertas saring Whatmann No. 41, untuk mendapatkan asap cair yang lebih jernih dibandingkan asap cair hasil pirolisis. Selanjutnya dilakukan proses destilasi. Asap cair yang dihasilkan pada proses destilasi ini adalah sebesar $736 \mathrm{ml}$ dengan rendemen $37,5 \%$. Sifat fisik asap cair hasil destilasi dapat dilihat pada Tabel .2.

Tabel .2. Sifat Fisik Asap Cair Hasil Destilasi

\begin{tabular}{cc}
\hline Parameter & Data \\
\hline Warna & Kuning keruh \\
Bau & Tidak berbau menyengat \\
Rendamen & $37,5 \%$ \\
\hline
\end{tabular}

Setelah itu asap cair yang telah di destilasi kemudian di redestilasi pada suhu yang sama yaitu 200 ${ }^{\circ} \mathrm{C}$. Jumlah destilat yang didapat pada redestilasi yaitu sebanyak $716 \mathrm{~mL}$ dengan rendemen $36,19 \%$. Untuk data fisik asap cair redestilasi dapat dilihat pada Tabel 3

Tabel 3. Sifat fisik asap cair hasil redestilasi

\begin{tabular}{cc}
\hline Parameter & Data \\
\hline Warna & Kuning jernih \\
Bau & Hampir tidak berbau asap \\
Rendamen & $36,19 \%$ \\
\hline
\end{tabular}

Pada penelitian ini didapatkan $\mathrm{pH}$ asap cair cangkang buah H.braziliensis memenuhi standar wood vinegar Jepang yaitu $\mathrm{pH}$ 2,548. $\mathrm{pH}$ standar wood vinegar Jepang yaitu bernilai 1,5 s/d 3,7 [9]. Besarnya kadar fenol pada asap cair tergantung dari jumlah lignin yang terkandung dari bahan baku asap cair. Fenol berasal dari penguraian lignin [10]. Kadar fenol asap cair cangkang buah H.braziliensis pada penelitian ini sebesar $0,84 \%$.

Hasil pengujian asap cair cangkang buah H.braziliensis terhadap bakteri S. aureus yang ditumbuhkan pada media agar ternyata menunjukkan kemampuan yang berbeda pada setiap konsentrasi yang diberikan.(Tabel 4)

Tabel 4 Diameter zona bening asap cair cangkang buah H.braziliensis terhadap bakteri S. aureus

\begin{tabular}{cccccc}
\hline \multirow{2}{*}{ Konsentrasi } & \multicolumn{3}{c}{ Ulangan } & Total & $\begin{array}{c}\text { Rata- } \\
\text { rata }\end{array}$ \\
\cline { 2 - 4 } & I & II & III & & 2 \\
\hline $5 \%$ & 2 & 2 & 2 & 6 & 2 \\
$10 \%$ & 3 & 4 & 4 & 11 & 3,6 \\
$25 \%$ & 7 & 7 & 7 & 21 & 7 \\
$50 \%$ & 9 & 9 & 9 & 27 & 9 \\
$75 \%$ & 11 & 11 & 10 & 32 & 10,6 \\
$100 \%$ & 122 & 11 & 12 & 35 & 11,6 \\
\hline
\end{tabular}

Berdasarkan Tabel 4 di atas, konsentrasi asap cair cangkang buah H.braziliensis yang efektif menghambat pertumbuhan bakteri $S$. aureus adalah 75\%.v/v Pada konsentrasi tersebut kekuatan antibakterinya sudah dikategorikan kuat karena menunjukan zona bening yang besar yaitu $10,6 \mathrm{~mm}$. Diameter zona bening konsentrasi asap cair $75 \% \mathrm{v} / \mathrm{v}$ dapat dilihat pada Gambar 1.

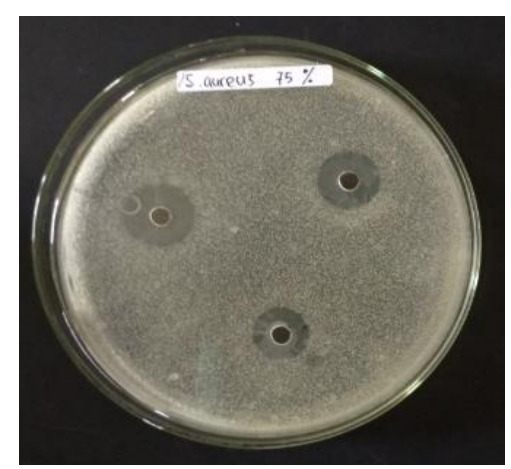

Gambar 1. Zona bening konsentrasi asap cair cangkang buah karet $75 \%$.v/v

Adanya fenol pada asap cair akan merusak membran sitoplasma sehingga menyebabkan kebocoran membran yang . memungkinkan ion organik nukleotida dan asam amino ikut keluar sel, sehingga akan mengganggu pertumbuhan bakteri dan juga dapat menyebabkan kematian bakteri. Keasaman pada asap cair akan mengasamkan sitoplasma, merusak tegangan permukaan membran dan hilangnya transport aktif makanan melalui membran sehingga menyebabkan destabilisasi bermacam-macam fungsi dan struktur komponen sel. Berdasarkan hasil perhitungan uji One Way ANOVA, diperoleh nilai $\mathrm{F}_{\text {hitung }}$ sebesar 268,8 dan nilai $F_{\text {tabel }}(0,95)(5,12)$ sebesar 3,10. Karena $F_{\text {hitung }} \geq F_{\text {tabel }}$ maka $\mathrm{H}_{0}$ ditolak, artinya terdapat perbedaan yang 
signifikan antara diameter zona bening dari berbagai variasi konsentrasi asap cair cangkang buah H.braziliensis

\section{KESIMPULAN}

Adapun dari hasil penelitian yang telah dilakukan diperoleh kesimpulan bahwa asap cair cangkang buah $H$.braziliensis mampu menghambat pertumbuhan bakteri $S$. aureus dengan parameter . memiliki $\mathrm{pH} \mathrm{pH}$ 2,548 dan kadar fenol 0,84\% . Konsentrasi asap cair cangkang buah H.braziliensis yang efektif menghambat pertumbuhan bakteri $S$. aureus adalah $75 \% \mathrm{v} / \mathrm{v}$ dengan diameter zona bening 10,6 $\mathrm{mm}$.

\section{SARAN}

Untuk penelitian lanjutan disarankan, Perlu dilakukan pirolisis dengan berbagai tingkatan suhu agar dapat mendapatkan senyawa-senyawa aktif pada asap cair dan Sebaiknya dilakukan analisis komponen kimia penyusun asap cair dengan menggunakan GC-MS untuk melihat seberapa banyak komponen yang terdapat pada asap cair. Perlu dilakukan uji toksisitas asap cair cangkang buah $H$. braziliensis untuk penggunaan asap cair cangkang buah karet lebih lanjut.

\section{UCAPAN TERIMAKASIH}

Penulis mengucapkan terimakasih kepada ketua laboraorium dan Laboran Fakultas FKIP Kimia UNIB, FKIK UNIB dan SBIH yang senantiasa membantu dan membimbing kelancaran penelitian, serta semua pihak yang telah banyak membantu dalam penyelesaian penelitian ini.

\section{DAFTAR PUSTAKA}

[1]. Andriani. Y, Mohamad, H. , 2013, Potential Therapeutic Lead Coumpouds From Our Local Coastal Forest, The 26th Symposium of Malaysia Analytical Sciences (SKAM 26), Khuching Serawak Malaysia, 4-5 December.

[2] Vinsiah, Rananda, Andi Suherman dan Desi 2015. Pembuatan Karbon Aktif Dari Cangkang Kulit Buah Karet. ejournal.unsri.ac.id (23 Desember 2016)
[3] Fadillah, Haris dan Alivia Alfiarty 2015. The Influence Of Pyrolysis Temperature And Time To The Yield And Quality of Rubber Fruit (Hevea brasiliensis) Shell Liquid Smoke. Prosiding Seminar Nasional Teknik Kimia Pengembangan Teknologi Kimia untuk Pengolahan Sumber Daya Alam Indonesia. Yogyakarta, 18 Maret

[4] Girrard, J. P. 1992. Smoking in Technology of Meat Production. Ellis Harwood Limited, New York. ISBN : 978-602-97522-0-5

[5] Andriani. Y, 2010, Study Correlation between antioxidant activity and total phenolics content of Phaleria macrocarpa leaves extract,UMTAS International conference, University Malaysia Terengganu (UMT) Kuala Terengganu Malaysia 6-8 Mei

[6] ] Jawetz, E, Menick, J.L, dan Adelberg, E.A. 2001. Mikrobiologi Kedokteran (Medical Microbiology). Ahli bahasa: Muhardi dan Bagian Mikrobiologi Fakultas kedokteran Universitas Airlangga. Edisi Pertama. Jakarta: Salemba Medika. ISBN : 979-3027-05-3

[7] Harborne, J.B. 1987. Metode Fitokimia Penuntun: Penuntun Cara Modern Menganalisis Tumbuhan. Diterjemahkan oleh: Kosasih Padmawinata dan Iwang Soediro. Terbitan Kedua. Bandung: Penerbit ITB. ISBN : 979-8001-14-1581

[9] Yatgai, Mitsuyoshi. 2002. Ultizatio of Charcoal and Wood Vinegar in japan. Graduate School of Agricultural and Life Science. Japan: The University of Tokyo

[10] Sutin, 2008. Pembuatan Asap Cair Dari Tempurung dan Sabut Kelapa Secara Pirolisis Serta Fraksinasinya Dengan Ekstraksi. http://repository.ipb.ac.id (3 Mei 2017)

Penulisan Sitasi Artikel ini ialah :

Agustina, W, Sumpono, Elvia, R, 2017. Aktivitas Asap Cair Cangkang Buah Hevea braziliensis Sebagai Anti Bakteri Staphylacoccus aureus. Alotrop, 1(1):6-9. 